\title{
ÍNDICE DE VANTAGEM COMPARATIVA REVELADA PARA O COMPLEXO SOJA DA REGIÃO CENTRO-OESTE BRASILEIRA
}

\author{
Revealed Comparative Advantage (RCA) for the soy complex for the Brazilian Central- \\ West region
}

Marciele de Freitas Oliveira1
Madalena Maria Schlindwein ${ }^{2}$

\begin{abstract}
Resumo: O Centro-Oeste brasileiro se destaca no setor agrícola por ser uma das principais regiões produtoras e exportadoras de grãos. O objetivo central desse trabalho foi fazer uma caracterização da exportação dos produtos do complexo soja na região Centro-Oeste. Além disso, buscou-se analisar a importância desses produtos para a região. Os dados utilizados nesta pesquisa referem-se à exportação dos produtos do complexo soja na região e no Brasil, oriundos do Sistema de Análise Exterior (ALICEWeb), da Secretaria de Comércio Exterior (SECEX) e do World Trade Organization (WTO). Como método de pesquisa, utilizou-se primeiramente o Índice de Vantagem Comparativa Revelada (IVCR), porém, como esse índice apresenta valores positivos assimétricos, recorreu-se ao Índice de Vantagem Comparativa Revelada Simétrica (IVCRS), a fim de suprir essa limitação, pois os valores do IVCRS variam entre -1 e 1 . Como resultado constatou-se que a região Centro-Oeste apresenta vantagens comparativas na exportação do complexo soja, porém essa vantagem vem apresentando queda nos últimos anos.
\end{abstract}

Palavras-chave: Vantagem Comparativa, Competitividade, Centro-Oeste

Abstract: The Brazilian Central-West Region distinguishes in the agricultural sector for being one of the main producing and exporting regions of seed. The objective of this paper is to make a description of the production and exportation of the soy culture in the Central-West Region. In addition, we analyzed the importance of these products to the region. The data used in this paper are related to the exportation of the soy complex products in the Central-West region and in and it is a result of the Exterior Analysis System (ALICEWeb), the Bureau of Foreign Trade (SECEX) and the World Trade Organization (WTO). As a research method, we used the Revealed Comparative Advantage (RCA) index, however, as this index presents asymmetrical positive values, we turned to the Revealed Symmetric Comparative Advantage (RSCA) index, in order to supply this limitation, given that the RSCA values may vary between -1 and 1 . As result, we verified that the Central-West region presents comparative advantages in the exportation of the soy complex, but this advantage is decreasing for the past years.

Key words: Revealed Comparative, Competitive Edge, Central-West

JEL: $A 10$

\footnotetext{
${ }^{1}$ Economista. Mestranda em Agronegócios pela Universidade Federal da Grande DouradosUFGD.marcielemfo@gmail.com

${ }^{2}$ Economista. Doutora em Economia Aplicada pela Escola Superior de Agricultura Luiz Queiroz- ESALQ-USP.

Professora da Universidade Federal da Grande Dourados. MadalenaSchlindwein@ufgd.edu.br
} 


\section{INTRODUÇÃO}

O Brasil é um dos principais produtores e exportadores mundiais de produtos agrícolas, sendo o segundo maior exportador de grão, farelo e óleo de soja. Na safra 2014/15, a produção brasileira da soja em grãos foi de 93,26 milhões de toneladas, enquanto a produção do farelo de soja ficou em 31,57 milhões de toneladas e o óleo de soja apresentou uma produção de 7,99 milhões de toneladas no mesmo período (CONAB, 2015).

De acordo com dados do Ministério da Agricultura e Abastecimento (2015), no acumulado do ano 2014, a balança comercial do complexo soja, no Brasil, mostrou alta de 1,40\% em seu valor exportado atingindo US\$31,40 bilhões. Em termos de quantidade exportada, o volume de comércio cresceu em $5,60 \%$, e o preço médio dos produtos do complexo soja caiu em $4,00 \%$, no mesmo período.

A região Centro-Oeste destaca-se por sua produção no setor agropecuário, sendo a principal produtora de soja no Brasil, com 14,37 milhões de hectares de área plantada na safra 2014/15, atingindo 43,14 milhões de toneladas do grão colhido. Ocorreu queda na produtividade em $0,1 \%$ em relação a safra de 2013/14. Neste período de 2014/15, a região foi responsável por $45,87 \%$ da produção nacional (CONAB, 2015).

A região Centro-Oeste atingiu US $\$ 27,35$ bilhões em sua exportação total, no ano de 2014 , valor que representou 56,25 milhões de toneladas. Ao comparar com a exportação do ano anterior, constata-se que ocorreu queda entre esses dois períodos, registrada em 3,61\%. (MDIC, 2015).

A exportação da soja em grão apresentou variação de $7,75 \%$ no valor exportado entre os anos de 2013 e 2014, sendo o produto que possui a maior participação na pauta de exportação da região Centro-Oeste. O farelo de soja ficou em terceiro lugar na pauta de exportação no ano de 2014, com queda de $7,56 \%$ em relação ao ano anterior. Enquanto isso, o óleo de soja bruto apresentou queda de $33,18 \%$ entre os anos de 2013 e 2014, caindo da $15^{\text {a }}$ posição, no ano de 2013 , para $17^{\text {a }}$ posição na pauta da exportação total da região Centro-Oeste no ano de 2014. E, o óleo refinado também apresentou queda, registrada em 2,09\%, entre os anos de 2013 e 2014. O produto ocupou a 31를 posição na pauta de exportação regional em 2014 (MDIC, 2015).

Devido à importância da soja na exportação brasileira e em suas Unidades Federativas, vários estudos têm sido realizados a fim de analisar, principalmente, os aspectos econômicos desta comercialização. No que se refere às Vantagens Comparativas Reveladas tem-se os estudos de: Souza e Ilha (2005) que analisaram o índice para a soja, a carne bovina e o frango; já Coronel et. al. (2009) analisaram a vantagem comparativa da soja para o Brasil; Coronel et. al. (2007) que analisaram essa vantagem para o estado de Mato Grosso do Sul e para a região de Ponta Porã; Dorneles, Dalazoana e Schlindwein (2013) que analisaram a vantagem comparativa para os produtos do complexo soja para o estado de Mato Grosso do Sul; entre outros autores. 
No que se refere os Centro-Oeste, indaga-se: essa região possui ou não vantagens comparativas em exportar produtos do complexo soja? Na tentativa de responder a este questionamento propõe-se, com este trabalho, verificar através do Índice de Vantagem Comparativa Revelada, o nível de competitividade da região Centro-Oeste no que se refere a exportação da soja em grão, do óleo e do farelo. Neste ínterim, o objetivo geral deste estudo é mensurar a evolução das vantagens comparativas das exportações dos produtos do complexo soja da região Centro-Oeste no período de 2002 a 2011.

Para tanto, o trabalho divide-se em quatro seções, além desta breve introdução. Na segunda seção, apresenta-se a metodologia com destaque para a área de estudo, o modelo teórico e os dados utilizados no estudo. Na terceira seção, destacam-se os resultados e a discussão dos dados. E, por fim, as considerações finais e as referências utilizadas no estudo fecham o trabalho.

\section{REVISÃO DE LITERATURA}

Esta revisão segue apresentando os estudos que foram feitos utilizando o Índice de Vantagem Comparativa para o mundo, para o Brasil e para as Unidades Federativas da região Centro-Oeste.

\subsection{Vantagem Comparativa no Mundo}

Havrila e Gunawarda (2003) analisaram as vantagens comparativas da Austrália nas indústrias têxteis e dos vestuários. A partir da aplicação do Índice de Vantagens Comparativas de Balassa os autores identificaram que a Austrália não possui vantagens comparativas no setor dos produtos têxteis e de vestuários em relação ao mundo. Assim, os autores consideraram que o país não possui competitividade mundial neste setor e que deveria adotar medidas - como o aumento em qualidade e design - para auferirem ganhos na quantidade exportada de seus produtos.

Mosona (2004) analisaram o nível de competitividade agrícola e integração da cadeia produtiva na África do Sul, Argentina e Austrália, para o período de 1995-1998. Através do calculo do Índice de Vantagens Comparativas os autores contataram que a África do Sul possui uma vantagem marginalmente competitiva em sua cadeia de alimentos agrícolas. Porém, para a Argentina e a Austrália os dados revelaram que possuem vantagens comparativas em suas cadeias alimentares. Mas ainda destacam que occeru uma diminuição no nível de competitividade quando os produtos passam por processo de agregação de valor.

Dieter e Englert (2006) analisaram através do Índice de Vantagens Comparativas Reveladas (RCA) a competitividade do setor de indústria florestal do país da Alemanha no mercado internacional. Constaram que apesar de a Alemanha ser a líder mundial deste setor, o RCA mostrou que a indústria de madeira não possui vantagens comparativas em relação ao mercado total. 
Podendo ser explicado pela mudança de competitividade de outros setores do país.

\subsection{Vantagem Comparativa no Brasil}

Nonnemberg (1991) utilizou o índice de Vantagem Comparativa Revelada Simétrica para a análise da indústria de transformação brasileira, entre 1980 e 1988. Essa fórmula foi desenvolvida por Lafay, em 1990. O autor analisou se as vantagens se baseiam nos custos relativos de fatores e no uso de recursos naturais. Com o estudo concluiu que os fatores precisam ser revitalizados para determinar 0 dinamismo brasileiro das vantagens comparativas. Ainda observou que, o país exporta mais produtos que tem intensa utilização de mão de obra e importa produtos com menor intensidade de mão de obra empregada.

Ao analisar se o comércio agrícola tinha como principal destino a União Europeia, Waquil et. al. (2004) concluíram que o país apresentou vantagens comparativas ao exportar, principalmente nos seguintes produtos: soja e derivados, suco de laranja, frango, açúcar e café. Coronel e Dessimon (2007) concluíram com o estudo que, a China tem sido um dos principais destinos da soja brasileira desde 1997. Mas com as barreiras tarifárias impostas pela China resulta em redução das exportações nos últimos anos.

Souza e llha (2005), com o objetivo de analisar a vantagem comparativa dos produtos do agronegócio brasileiro para o período de 1992 a 2002, constatou que o país apresentou vantagem comparativa crescente durante 0 período analisado. Coronel et. al. (2009), a partir do Índice de Vantagens Comparativas Reveladas (IVCR), buscou analisar a exportação de grãos, farelo e óleo de soja brasileiro no período de 1995 a 2004. Os autores concluíram que o país apresentou vantagens comparativas no complexo da soja durante todo 0 período analisado. Porém, indicaram que o Brasil deveria investir mais na exportação do farelo e do óleo, porque ambos têm maior valor agregado que a soja em grão (CORONEL et. al., 2009).

\subsection{Vantagem Comparativa na Região Centro-Oeste}

Mesquita (2006) analisou a existência de vantagem comparativa entre os principais segmentos da pauta de exportação do estado de Goiás, no período entre 1997 e 2003. Os setores analisados foram: Agropecuária, extração de minerais metálicos e não-metálicos, alimentos e bebidas, entre outros. Abordando também, assim como Nonnemberg (1991), a fórmula desenvolvida por Lafay (1990).

Para Mesquita (2006), os produtos que apresentavam maior vantagem comparativa, no ano de 2002, foram os agropecuários, seguidos dos alimentos e bebidas, produtos primários derivados e extração de minerais não metálicos. 
Os produtos que mostraram vantagem nula foram: móveis, madeira, brinquedos, edição e impressão, entre outros. Os produtos nos quais não se verificam vantagens comparativas foram: veículos automotores, produtos minerais não-metálicos, produtos metálicos, química, entre outros.

O estado de Goiás possui vantagens econômicas principalmente nos produtos ligados a atividades agropecuárias, em produtos com comércio muito volátil. Por isso, é preciso o desenvolvimento de políticas que invistam em setores de produtos com maior valor agregado, como os veículos automotores, máquinas e equipamentos (MESQUITA, 2006).

Coronel et.al. (2007) analisaram o Índice de Vantagem Comparativa para a produção de soja no estado de Mato Grosso do Sul e da região de Ponta Porã, no período de 1990 a 2004. O índice utilizado foi o desenvolvido por Balassa (1965 e 1977). Os resultados mostraram o índice positivo, durante o período analisado, tanto para o estado de Mato Grosso do Sul quanto para a cidade de Ponta Porã. Porém, esse índice apresenta oscilações, por exemplo, em 1998 o índice caiu em 59,18\% em relação ao ano anterior. No total do período analisado, Ponta Porã apresentou aumento no índice em 147,07\%, enquanto, para o estado de Mato Grosso do Sul, o índice apresentou queda em $25,69 \%$.

Tonhá et. al. (2010) analisaram a competitividade da exportação da carne bovina brasileira, entre 2000 e 2006. Destacaram que a região CentroOeste apresentou a maior competitividade ao ser comparada com a carne bovina brasileira. E, também, em os estados da região Centro-Oeste ocorreu vantagem comparativa revelada. Com destaque para o estado de Mato Grosso do Sul que foi mais competitivo na exportação de carne bovina até mesmo ao ser comparada com alguns concorrentes brasileiros.

Dorneles, Dalazoana e Schlindwein (2013) que analisaram a vantagem comparativa para os produtos do complexo soja para o estado de Mato Grosso do Sul em relação ao Brasil. Constataram que o estado possui vantagem comparativa em exportar os grãos e o farelo de soja. Enquanto o óleo de soja não apresentou vantagens comparativas.

\section{METODOLOGIA}

\section{1. Área de Estudo}

A região Centro-Oeste brasileira é composta pelas seguintes Unidades Federativas: Mato Grosso, Mato Grosso do Sul, Goiás e o Distrito Federal. De acordo com o Instituto Brasileiro de Geografia e Estatística - IBGE (2014), a região Centro-Oeste tem um território de 1,61 milhões $\mathrm{km}^{2}$ (representa cerca de $18,90 \%$ do território nacional) e densidade demográfica de $9,45 \mathrm{hab} . / \mathrm{km}^{2}$. Faz divisa com todas as regiões brasileiras, além de fazer fronteira com o Paraguai e Bolívia. Estima-se uma população de 15,22 milhões de habitantes, no ano de 2014, para a região Centro-Oeste. 
A agropecuária é de grande importância para a região Centro-Oeste e suas Unidades Federativas. Destacando-se na produção agrícola, a produção de soja (responsável por $46,81 \%$ da produção nacional, na safra de 2013 , com rendimento de 2,93 t/ha), cana de açúcar $(17,12 \%)$ e milho (44,68\%). E, os seus estados estão entre os 10 principais produtores agrícolas nacionais (IBGE, 2013).

A produção industrial está crescendo e se fortalecendo ao longo da primeira década do século XXI. No Centro-Oeste, destaca-se, a fabricação de produtos alimentícios, cujo valor da transformação industrial representou $50,19 \%$ do total, demonstrando a importância, mais uma vez, da agricultura nessa região (IBGE, 2012).

\subsection{Modelo Teórico}

O modelo teórico é baseado no Índice de Vantagens Comparativas (IVCR), que foi inspirado na Lei das Vantagens Comparativas de David Ricardo, de 1817. O primeiro a desenvolver esse índice foi Balassa (1965), julgando que o comércio exterior mostraria as vantagens comparativas de um país, e formulando um índice que considerava apenas as exportações, pois para o autor as importações eram influenciadas pelas barreiras protecionistas. Assim, o índice das vantagens comparativas de Balassa pode ser expresso como:

$$
I V C R i j=\frac{X i j}{X j} / \frac{X i w}{X w}
$$

Em que:

IVCRij = Índice de Vantagem Comparativa Revelada do produto $i$ pela região j;

$X i j=$ exportação de um produto $i$ pela região $j$;

$X j=$ exportação total da região $j$;

$X i w=$ exportação do produto $i$ pela região $w$;

$X w=$ exportação total da região $w$;

jou $w$ = regiões exportadoras;

$i=$ produto exportado.

Assim, a intuição da fórmula indica que, se o índice for menor que 1, a região não possui vantagem comparativa revelada na exportação do bem $i$; se o índice for superior a 1 a região possui vantagem comparativa revelada na exportação desse produto; e, se for igual a 1, a região não apresenta vantagem e nem desvantagem comparativa (MAIA, 2001).

Porém esse índice apresenta uma limitação, o fato de ser assimétrico para os valores superiores a unidade. Devido a isso, Laursen (1998) desenvolveu o Índice de Vantagem Comparativa Revelada Simétrica: 


$$
I V C R S i j=\frac{I V C R i j-1}{I V C R i j+1}
$$

Em que:

IVCRSij= Índice de Vantagem Comparativa Revelada Simétrica do produto $i$ da região $j$.

IVCRij= Índice de Vantagem Comparativa Revelada do produto $i$ pela região $j$.

Nesse índice os valores variam entre -1 e 1 . Se os valores resultantes estiveram no intervalo de -1 a 0 , não se constata vantagem comparativa, ou seja, a região possui desvantagem na exportação do determinado produto. Caso os valores estejam entre $0 \mathrm{e}+1$, indica que a região possui vantagem comparativa em exportar o produto (LAURSEN, 1998).

\subsection{Modelo Empírico}

Para a análise da competitividade da exportação dos produtos do complexa soja da região Centro-Oeste brasileira, se utilizará o Índice de Vantagem Comparativa Revelada, dado pela seguinte equação:

$$
I V C R s c=\frac{X s c}{X c} / \frac{X s b}{X b}
$$

Onde:

IVCRsc = Índice de Vantagem Comparativa Revelada da soja em grão ou em óleo ou em farelo pela a região Centro-Oeste;

$X s c=$ exportação da soja em grão ou em óleo ou em farelo pela região CentroOeste;

$X_{c}=$ exportação total da região Centro-Oeste;

$X s b$ = exportação da soja em grão ou em óleo ou em farelo pelo Brasil;

$X b=$ exportação total do Brasil;

$c=$ região Centro-Oeste;

$b=$ Brasil;

$s=$ Soja em grão, óleo ou farelo.

A análise será realizada para o período de 2002 à 2011. Os produtos do complexo soja utilizados serão: a soja em grão, o óleo de soja e o farelo de soja. Para o Índice de Vantagem Comparativa Revelada Simétrica será utilizada a seguinte equação: 


$$
I V C R S s C=\frac{I V C R s c-1}{I V C R s c+1}
$$

Onde:

IVCRSsC = Índice de Vantagem Comparativa Simétrica da soja em grão, ou em óleo, ou em farelo pela região Centro-Oeste.

IVCRsc = Índice de Vantagem Comparativa Revelada da soja em grão, ou em óleo, ou em farelo pela região Centro-Oeste.

O cálculo desse índice foi realizado para os anos de 2002 a 2011, assim como no índice de Vantagem Comparativa Revelada (fórmula 5). E, também serão analisados os mesmos produtos exportados do complexo soja: o grão, o óleo e o farelo.

\subsection{Fonte de Dados}

Para o desenvolvimento da pesquisa foram utilizados dados de exportação dos produtos do complexo soja e exportações totais tanto da região Centro-Oeste quanto do Brasil. Os dados referentes à exportação (FOB) totais e dos produtos do complexo soja, são oriundos do Sistema de Análise de Comércio Exterior (ALICEWeb), da Secretaria de Comércio Exterior (SECEX) e do World Trade Organization (WTO).

Os dados de exportação oriundos do WTO estavam disponíveis até o ano de 2011. Por isso, na análise da exportação e do Índice de Vantagens Comparativas Reveladas o período de analise é referente ao período de 2002 a 2011.

\section{RESULTADOS E DISCUSSÃO}

Nesta seção estão demonstrados os dados sobre a exportação dos produtos do complexo soja, comparando a região Centro-Oeste, suas Unidades Federativas e as médias brasileiras. E, ainda, os resultados do Índice de Vantagem Comparativa Revalada e do Índice de Vantagem Comparativa Revelada Simétrica.

\subsection{Exportação do Complexo Soja}

Nesta seção serão explanados os dados correspondentes a exportação de soja em grão, do óleo e do farelo da soja, no período de 2002 a 2011. Os 
dados de cada produto do complexo soja serão comparados entre os valores das Unidades Federativas da região Centro-Oeste e do Brasil. Na Tabela 1 constam os dados referentes a exportação da soja em grão do Brasil, da região Centro-Oeste e de suas Unidades Federativas, entre os anos de 2002 e 2011.

Tabela 1 - Comparação da evolução da exportação de soja em grãos, entre as Unidades Federativas da região Centro-Oeste, com sua média regional e nacional, US\$ em milhões, período de 2002 a 2011

\begin{tabular}{l|c|c|c|c|c|c}
\hline ANOS & BRASIL & $\begin{array}{c}\text { CENTRO- } \\
\text { OESTE }\end{array}$ & $\begin{array}{c}\text { MATO } \\
\text { GROSSO }\end{array}$ & $\begin{array}{c}\text { MATO GROSSO } \\
\text { DO SUL }\end{array}$ & GOIÁS & $\begin{array}{c}\text { DISTRITO } \\
\text { FEDERAL }\end{array}$ \\
\hline $\mathbf{2 0 0 2}$ & 3029,18 & 1203,73 & 980,59 & 26,25 & 175,97 & 20,93 \\
$\mathbf{2 0 0 3}$ & 4287,03 & 1566,30 & 1033,66 & 50,49 & 474,01 & 8,14 \\
$\mathbf{2 0 0 4}$ & 5388,43 & 1989,63 & 1367,93 & 102,68 & 511,80 & 7,23 \\
$\mathbf{2 0 0 5}$ & 5341,29 & 3125,32 & 2136,52 & 235,12 & 738,56 & 15,13 \\
$\mathbf{2 0 0 6}$ & 5659,66 & 3172,07 & 2263,29 & 262,78 & 633,24 & 12,76 \\
$\mathbf{2 0 0 7}$ & 6702,97 & 2819,71 & 1889,22 & 294,15 & 628,09 & 8,26 \\
$\mathbf{2 0 0 8}$ & 10945,35 & 5321,35 & 3749,86 & 457,68 & 1096,26 & 17,55 \\
$\mathbf{2 0 0 9}$ & 11413,00 & 5503,38 & 4227,48 & 311,15 & 944,39 & 20,37 \\
$\mathbf{2 0 1 0}$ & 11035,21 & 4642,06 & 3289,96 & 509,15 & 829,65 & 13,31 \\
$\mathbf{2 0 1 1}$ & 16312,23 & 6695,05 & 4773,33 & 695,53 & 1192,00 & 34,20 \\
\hline
\end{tabular}

Fonte: Elaboração própria a partir de dados do AliceWeb (2013), MdicSecex (2002 a 2011) e WTO (2013).

A exportação do grão de soja apresentou aumento significante em todas as Unidades Federativas da região Centro-Oeste, no período entre 2002 e 2011, como mostram os dados da Tabela 1. O estado de Mato Grosso do Sul apresentou grande crescimento em seu valor exportado, que no ano de 2002 era de US\$ 26,25 milhões passando para US\$ 695,33 milhões em 2011. Outros crescimentos registrados ocorreram no estado de Goiás, com aumento de $577,40 \%$ e no estado de Mato Grosso, 386,78\%. O Distrito Federal exportou US\$ 34,20 milhões de soja em grãos no ano de 2011.

De acordo com os dados que constam na Tabela 1, a participação de cada estado na pauta de exportação da soja em grãos na região Centro-Oeste, no ano de 2011, ficou da seguinte forma: estado de Mato Grosso com 71,30\%; Goiás com 17,80\%; Mato Grosso do Sul com 10,39\%; e, o Distrito Federal que representou $0,51 \%$ do total. Em relação a exportação nacional do grão, no mesmo período da analise anterior, configura-se da seguinte maneira a participação dessas Unidades Federativas: Mato Grosso (29,26\%); Goiás (7,31\%); Mato Grosso do Sul (4,26\%); e, Distrito Federal com 0,21\%.

A participação da exportação de soja em grão da região Centro-Oeste, em comparação à exportação nacional do mesmo produto, era de $39,74 \% \mathrm{em}$ 2002 passando para $41,04 \%$ no ano de 2011 . O crescimento da exportação deste produto da região Centro-Oeste, no período entre 2002 e 2011, foi da ordem de 456,19\%. Enquanto a exportação nacional de soja cresceu, no mesmo período, em $438,50 \%$. A evolução do valor da exportação de soja em grãos pode ser observada na Figura 1. 
Figura 1 - Comparação da exportação de Soja em grãos, US\$ em milhões, no Brasil e na região Centro-Oeste, período de 2002 a 2011

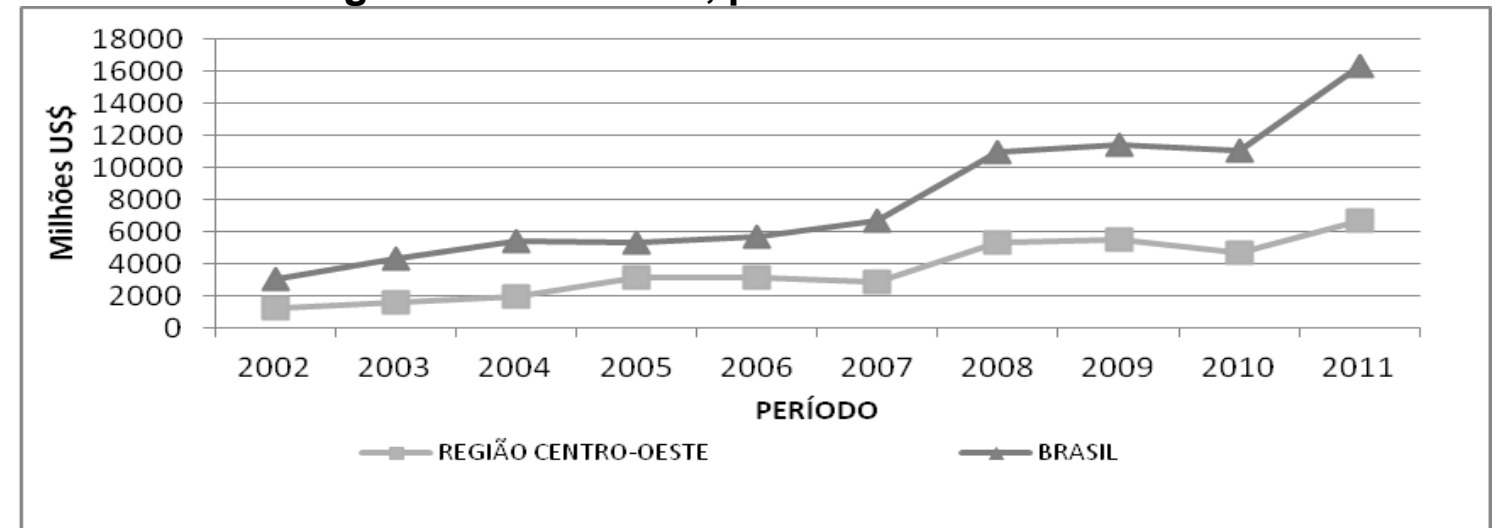

Fonte: Elaboração própria a partir de dados do AliceWeb (2013), MdicSecex (2002 a 2011) e WTO (2013).

A participação da exportação de soja da região Centro-Oeste, na exportação brasileira do mesmo produto, apresentou picos no ano de 2005, conforme pode ser observado na Figura 1, sendo responsável por $58,51 \%$ da exportação nacional da soja em grãos. Após esse ano, percebe-se que começa a aumentar a distância entre os valores de exportação da soja, ou seja, a participação da região Centro-Oeste começa a apresentar queda em relação a exportação nacional desse produto, atingindo 41,04\% no ano de 2011.

No que se refere a exportação do óleo de soja não foram encontrados valores para o Distrito Federal. A partir dos dados da Tabela 2, constata-se que o estado de Mato Grosso apresentou queda de participação na pauta regional da exportação do óleo de soja, pois em 2002 representava 82,17\% caindo para $66,50 \%$ em 2011. Mesmo com essa queda ainda é o estado que obteve 0 maior valor exportado em todo o período analisado, na região Centro-Oeste.

A partir dos dados da Tabela 2, constata-se que, a participação dos demais estados na pauta da exportação do óleo de soja da região CentroOeste, no ano de 2011, foi: Mato Grosso do Sul com 16,54\% e Goiás com $3,18 \%$. Ao comparar os valores com a exportação nacional do óleo de soja, constatou-se que todos os estados, da região Centro-Oeste, apresentaram aumento na participação neste segmento, no período de 2002 a 2011. Assim, no ano de 2011, o estado de Mato Grosso representou, em termos de valor exportado, $18,56 \%$ da exportação de óleo de soja no Brasil, o estado de Mato Grosso do Sul 4,62\% e o estado de Goiás 0,89\%.

O óleo de soja na região Centro-Oeste é um produto que apresentou crescimento na participação do valor em relação à exportação nacional do óleo de soja. Obtendo crescimento na sua participação de 15,03\% em 2002, passando para $27,92 \%$ no ano de 2011. 
Tabela 2 - Comparação da evolução do valor da exportação do óleo de soja, entre as Unidades Federativas da região Centro-Oeste, com sua média regional e nacional, US\$ em milhões, período de 2002 a 2011.

\begin{tabular}{l|lll|l|l}
\hline ANO & BRASIL & $\begin{array}{l}\text { CENTRO- } \\
\text { OESTE }\end{array}$ & $\begin{array}{l}\text { MATO } \\
\text { GROSSO }\end{array}$ & $\begin{array}{l}\text { MATO GROSSO } \\
\text { DO SUL }\end{array}$ & GOIÁS \\
\hline $\mathbf{2 0 0 2}$ & 778,06 & 116,92 & 96,07 & 5,40 & 6,24 \\
$\mathbf{2 0 0 3}$ & 1232,55 & 215,03 & 160,48 & 19,95 & 0,00 \\
$\mathbf{2 0 0 4}$ & 1382,09 & 346,99 & 239,65 & 57,16 & 9,56 \\
$\mathbf{2 0 0 5}$ & 1266,64 & 442,13 & 316,39 & 54,63 & 1,61 \\
$\mathbf{2 0 0 6}$ & 1228,64 & 255,98 & 121,98 & 12,83 & 4,24 \\
$\mathbf{2 0 0 7}$ & 1719,71 & 358,37 & 135,45 & 41,12 & 14,98 \\
$\mathbf{2 0 0 8}$ & 2670,69 & 602,47 & 399,77 & 60,25 & 19,39 \\
$\mathbf{2 0 0 9}$ & 1233,92 & 387,90 & 287,33 & 37,92 & 12,80 \\
$\mathbf{2 0 1 0}$ & 1352,43 & 342,54 & 257,19 & 53,34 & 9,87 \\
$\mathbf{2 0 1 1}$ & 2129,27 & 594,43 & 395,28 & 98,32 & 18,92 \\
\hline
\end{tabular}

Fonte: Elaboração própria a partir de dados do AliceWeb (2013), MdicSecex (2002 a 2011) e WTO (2013).

Com destaque para o ano de 2005, em que apresentou a maior participação, registrada em 34,91\% e também para o ano de 2009 (31,44\%), como pode ser observado na Figura 2. De acordo com dados do MDIC (2011), ao comparar o valor de óleo exportado pela região Centro-Oeste com o total de exportações do Brasil, constata que, o produto também apresenta acréscimo em sua participação na exportação nacional, que passou de $0,19 \%$ no ano de 2002 para $0,23 \%$ no ano de 2011.

Figura 2 - Comparação do valor da exportação do óleo de Soja, US\$ em milhões, no Brasil e na região Centro-Oeste, período de 2002 a 2011

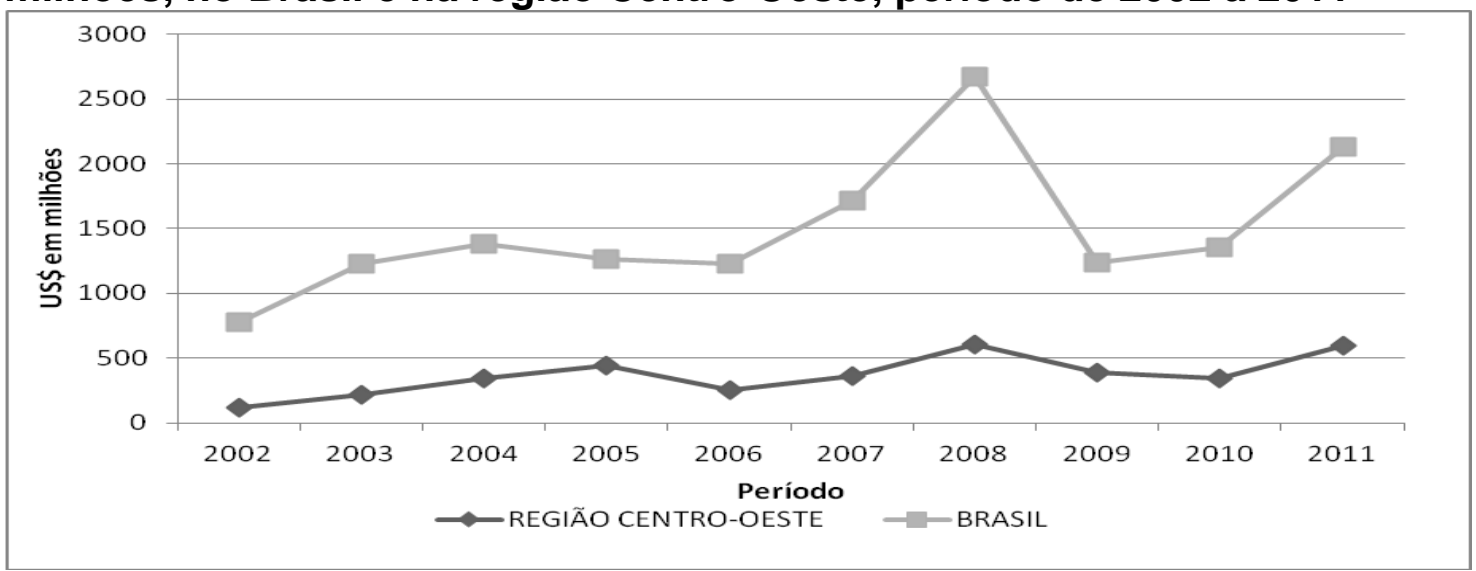

Fonte: Elaboração própria a partir de dados da AliceWeb/Mdic (2013), MdicSecex (2002 a 2011) e OMC (2013).

Destaca-se, na Figura 2, o aumento na exportação de óleo entre os períodos de 2006 e 2008, em que foi de 117,37\% para o Brasil e de 135,36 para a região Centro-Oeste. De acordo com a Companhia Nacional de Abastecimento - CONAB (2008), esse aumento pode ser explicado pelo bons preços do produtos e pelo aumento da demanda externa pelos produtos do complexo soja. Tanto que nesta safra de 2007/08 ocorreu incremento na área 
cultivada ligados as condições climáticas favoráveis durante o ciclo da lavoura e bom combate às pragas e doenças. Já a Safra de 2009 pode ser explicada como sendo reflexo do mercado internacional mediante a crise econômica ocorrida neste período.

Na Figura 2, é possível observar a evolução dos valores da exportação de óleo de soja da região Centro-Oeste e do Brasil. Constata-se que a região Centro-Oeste pode estar deixando de ganhar com o comércio deste produto, ou seja, está exportando mais o produto primário ao invés do óleo de soja que possui o maior valor agregado entre os produtos do complexo soja. $O$ investimento neste ramo proporcionaria o aprimoramento das tecnologias industriais na região e diversificação na pauta de exportação, que tem como principais produtos o grãos in natura.

Para Filho e Belik (2010), o Brasil está trilhando um caminho contrário a tendência mundial. Pois enquanto os concorrentes brasileiros procuram exportar produtos do complexo soja processados e com agregação de valor, o Brasil incentiva a exportação do grão in natura. Adotando política de redução da tarifa do Imposto sobre Circulação de Mercadorias e Serviços (ICMS) sobre a soja in natura.

No que refere aos dados da comparação do valor da exportação do farelo de soja no Brasil, na Região Centro-Oeste e em suas Unidades Federativas, pode ser visto na Tabela 3. Contata-se que valor da exportação do farelo da soja na região Centro-Oeste, durante o período analisado, apresentou crescimento em todos os estados que compõe essa região.

Tabela 3 - Comparação da evolução do valor da exportação do farelo de soja, entre as Unidades Federativas da região Centro-Oeste, com sua média regional e nacional, US\$ em milhões, período de 2002 a 2011

\begin{tabular}{l|c|c|c|c|c}
\hline ANO & BRASIL & $\begin{array}{c}\text { CENTRO- } \\
\text { OESTE }\end{array}$ & $\begin{array}{c}\text { MATO } \\
\text { GROSSO }\end{array}$ & $\begin{array}{c}\text { MATO GROSSO } \\
\text { DO SUL }\end{array}$ & GOIÁS \\
\hline $\mathbf{2 0 0 2}$ & 2198,96 & 647,76 & 409,87 & 100,59 & 137,30 \\
$\mathbf{2 0 0 3}$ & 2602,52 & 780,49 & 509,84 & 89,19 & 181,46 \\
$\mathbf{2 0 0 4}$ & 3270,96 & 1010,03 & 706,86 & 40,31 & 262,86 \\
$\mathbf{2 0 0 5}$ & 2865,66 & 1152,57 & 748,56 & 123,96 & 280,06 \\
$\mathbf{2 0 0 6}$ & 2419,81 & 923,98 & 604,11 & 111,87 & 208,01 \\
$\mathbf{2 0 0 7}$ & 2958,78 & 1112,75 & 725,85 & 154,44 & 232,47 \\
$\mathbf{2 0 0 8}$ & 4364,15 & 1945,7 & $1.229,94$ & 204,36 & 511,41 \\
$\mathbf{2 0 0 9}$ & 4592,79 & 2194,52 & $1.464,60$ & 184,02 & 545,90 \\
$\mathbf{2 0 1 0}$ & 4719,41 & 2256,67 & $1.554,50$ & 171,71 & 530,46 \\
$\mathbf{2 0 1 1}$ & 5697,92 & 2375,80 & $1.654,94$ & 149,62 & 571,24 \\
\hline
\end{tabular}

Fonte: Elaboração própria a partir de dados do AliceWeb (2013), MdicSecex (2002 a 2011) e WTO (2013).

Destaque-se, a partir dos dados da Tabela 3, que o maior crescimento ficou registrado no estado de Goiás com 316,06\%, seguido do estado de Mato Grosso, em que o valor da exportação do farelo de soja cresceu em 303,77\% e 
em Mato Grosso do Sul, esse aumento foi de 48,74\%, entre os anos de 2002 e 2011. No que se refere a exportação deste produto pelo Distrito Federal não foram encontrados valores disponíveis para este período.

Pode-se destacar que o estado do Mato Grosso possui maior participação no valor da exportação do farelo de soja na região Centro-Oeste, conforme dados da Tabela 3 . No ano de 2002, este estado foi responsável por $63,27 \%$ do valor total do farelo exportado na região e aumentou para $69,66 \%$, no período de 2011. O estado de Goiás também obteve aumento na participação da exportação do farelo de soja, que era de $21,19 \%$ aumentando para $24,04 \%$ nos anos de 2002 e 2011 , respectivamente.

Porém, o estado de Mato Grosso do Sul apresentou queda, em termos de participação, devido ao crescimento de sua exportação ter sido inferior aos dos demais estados, sendo que, em 2011, sua participação ficou em 6,30\%. Dorneles, Dalazoana e Schlindwein (2013) em seu estudo para as vantagens comparativas no estado de Mato Grosso do Sul, também constataram queda na exportação de farelo em 2011. As autoras apontaram que esse fenômeno ocorreu devido consolidação do setor de carnes brasileiro que aumenta a demanda interna pelo farelo de soja para alimentação do animal.

Ao comparar o valor da exportação do farelo da soja regional com o nacional, constata-se que ocorreu aumento na participação do produto exportado do Centro-Oeste, conforme pode ser observado na Figura 3. Em 2002 a exportação do farelo de soja na região Centro-Oeste representava $29,46 \%$ do farelo nacional exportado, passando para 41,70\% no ano de 2011. Destaca-se o ano de 2010, em que a região obteve maior participação na exportação do farelo, registrado em $47,82 \%$.

\section{Figura 3 - Comparação do valor da exportação do farelo de soja, US\$ em} milhões, no Brasil e na região Centro-Oeste, período de 2002 a 2011.

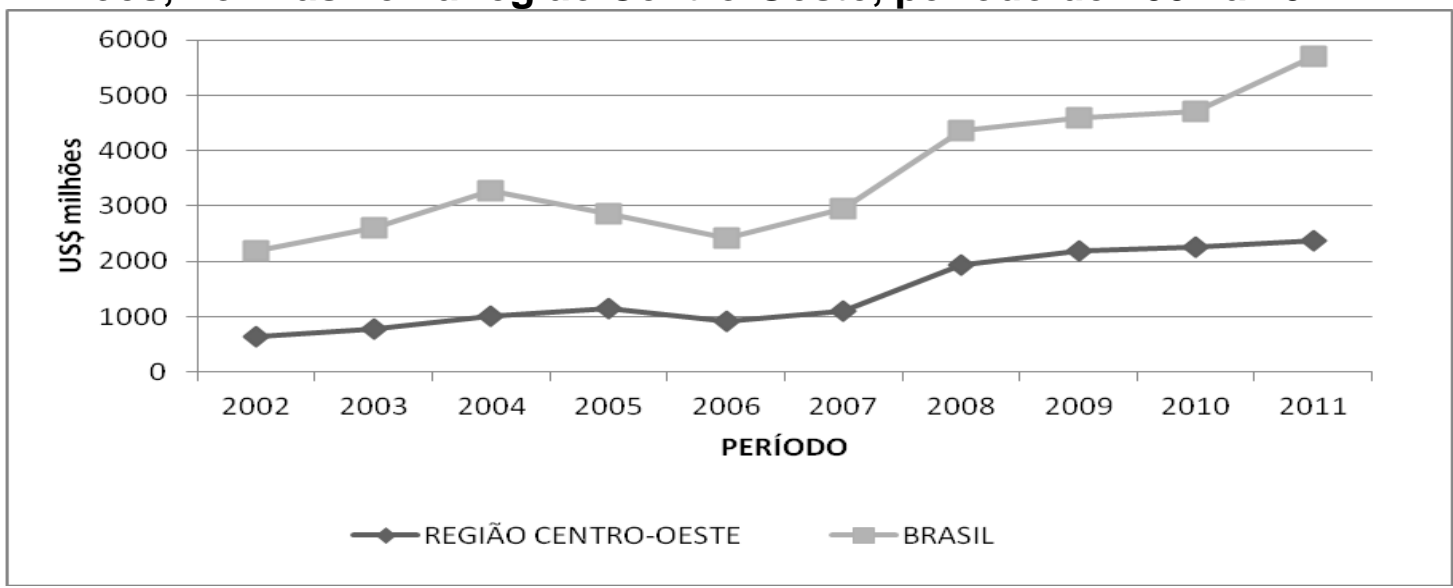

Fonte: Elaboração própria a partir de dados do AliceWeb (2013), MdicSecex (2002 a 2011) e WTO (2013).

Porém, ao comparar o valor da exportação do farelo de soja da região Centro-Oeste com o valor total da exportação regional, constata-se que ocorreu queda na participação deste produto na pauta de exportação. No ano de 2002, a participação era de $22,68 \%$ caindo para $7,97 \%$, no último período analisado. Ao comparar com a exportação total nacional, a participação do produto 
também apresenta queda durante o período, sendo de 1,07\% (2002) para 0,93\% (2011) (MDIC, 2011).

\section{2. Índice de Vantagens Comparativos Reveladas e Índice Simétrico}

A fim de analisar a importância do complexo soja para a região CentroOeste, pode-se verificar, na Tabela 4, os resultados obtidos através do Índice de Vantagens Comparativas Reveladas (IVCR) e do Índice de Vantagens Comparativas Simétricas (IVCRS).

Assim, de acordo com os dados na Tabela 4, percebe-se que os valores do IVCR são valores positivos em todo o período e superior a unidade. Portanto, pode-se afirmar que a região Centro-Oeste possui Vantagem Comparativa Revelada no Brasil para a exportação de soja em grão. Ainda, pode-se destacar que a soja em grão é um produto importante na pauta de exportação desta região.

Tabela 4 - Vantagem Comparativa Revelada e Vantagem Comparativa Revelada Simétrica para a soja em grão, entre a região Centro-Oeste e o Brasil, período de 2002 a 2011.

\begin{tabular}{l|c|c}
\hline ANO & IVCR & IVCRS \\
$\left(\mathbf{X}_{\mathrm{ij}} / \mathbf{X}_{\mathbf{j}}\right) /\left(\mathbf{X}_{\mathbf{i w}} / \mathbf{X}_{\mathbf{w}}\right)$ & $($ IVCR-1)/(IVCR+1) \\
\hline $\mathbf{2 0 0 2}$ & 8,41 & 0,79 \\
$\mathbf{2 0 0 3}$ & 7,04 & 0,75 \\
$\mathbf{2 0 0 4}$ & 6,88 & 0,75 \\
$\mathbf{2 0 0 5}$ & 9,66 & 0,81 \\
$\mathbf{2 0 0 6}$ & 10,30 & 0,82 \\
$\mathbf{2 0 0 7}$ & 6,97 & 0,75 \\
$\mathbf{2 0 0 8}$ & 6,79 & 0,74 \\
$\mathbf{2 0 0 9}$ & 5,26 & 0,68 \\
$\mathbf{2 0 1 0}$ & 5,44 & 0,69 \\
$\mathbf{2 0 1 1}$ & 3,53 & 0,56 \\
\hline
\end{tabular}

Fonte: Resultados da pesquisa.

Percebe-se, também, que ao comparar os anos de 2002 e 2011 o índice apresentou queda, como mostram os dados da Tabela 4. Devido a dimensão assimétrica do IVCR, utiliza-se o Índice de Vantagens Comparativas Reveladas Simétricas (IVCRS) para comprovar se a exportação do produto é vantajosa. Assim, como os valores apresentados pelo IVCRS estão contidos dentro do intervalo de 0 e 1, pode-se mais uma vez enfatizar que a região Centro-Oeste possui vantagem comparativa na exportação da soja em grão.

Comparando os resultados obtidos com o estudo de Dorneles, Dalazoana e Schlindwein (2013), que analisaram o Índice de Vantagens Comparativas para a exportação de soja no estado de Mato Grosso do Sul, constatou-se, que os valores obtidos no estudo também foram superiores a 
unidade, destacando que o estado também possui vantagem na exportação do produto em relação a exportação brasileira.

$\mathrm{Na}$ Figura 4, consta-se a comparação da evolução do Índice de Vantagem Comparativa Revelada e do Índice Simétrico para a soja in natura. Ao comparar a evolução dos índices para o período de 2002 com 2011, constata-se que ocorreu queda. O maior valor de ambos os índices foi registrado no ano de 2006, respectivamente, com 10,30 e 0,82.

Figura 4 - Comparação da evolução do IVCR e IVCRS para a soja em grão, entre a região Centro-Oeste e Brasil, período de 2002 a 2011.

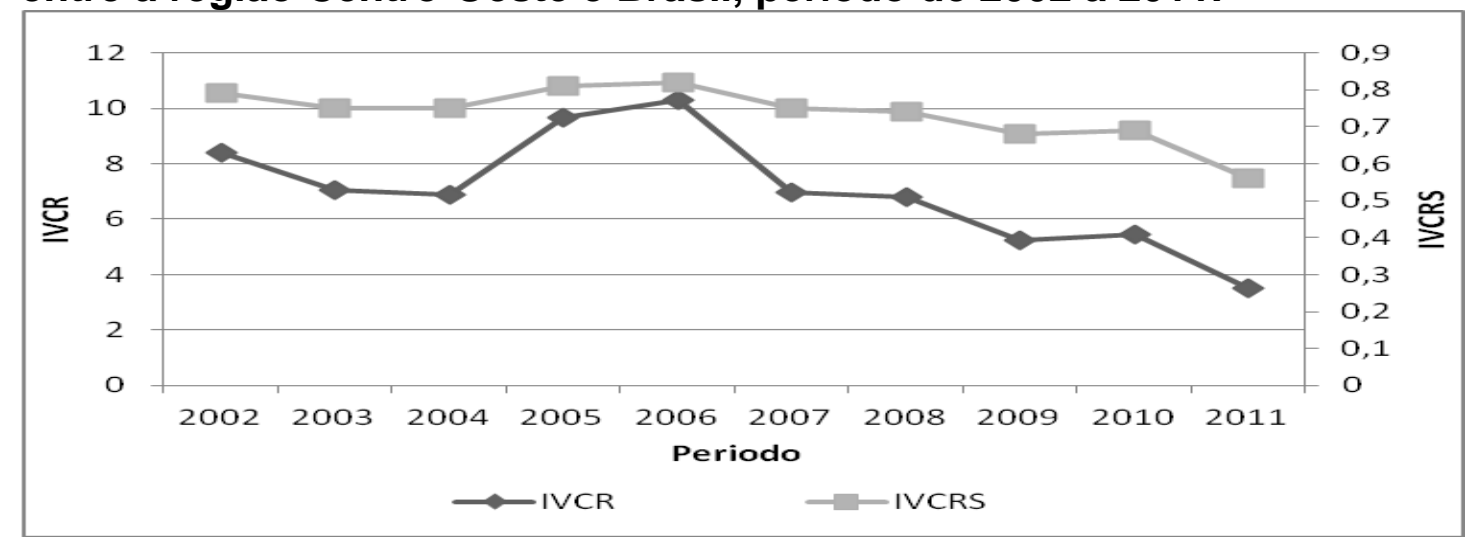

Fonte: Resultados da pesquisa.

Tanto o Índice de Vantagem Comparativa Revelada quanto o Índice Simétrico para a soja in natura apresentam uma tendência de queda a partir do ano de 2006, como pode ser visto na Figura 4. O que pode ser explicado por problemas climáticos que a região Centro-Oeste enfrentou no período de 2006. Outro fato que merece destaque é a crise internacional, ocorrida no ano de 2008, a qual trouxe respaldo negativo ao comércio internacional em alguns setores. E preciso ficar atento a essa queda nas vantagens comparativas desse produto, principalmente no ano de 2011, pois caso esse cenário persista é preciso adotar medida de reversão.

Outro produto analisado neste estudo foi o óleo de soja, cujos dados do IVCR e IVCRS estão apresentados na Tabela 5. No que se refere a Vantagem Comparativa Revelada, pode-se destacar que este produto também obteve valores positivos e diferentes da unidade. Sendo assim, constata-se que a região Centro-Oeste também possui vantagem em exportá-lo, assim como 0 caso da soja em grão.

Apesar da exportação do óleo de soja apresentar valores positivos em todo o período analisado, entre 2002 e 2011, seu IVCR está apresentando oscilação nos últimos períodos, atingindo 2,40 em 2011. Como se pode ver na Tabela 5, o maior IVCR foi apresentado no ano de 2005, sendo de 5,77 e, o menor, foi de 2,40, em 2011. Dentre alguns fatores, essa oscilação pode ser indicada de acordo com dados da CONAB (2012), pela grande demanda de consumo interno do produto, que chega a atingir $80,00 \%$ da produção em alguns períodos.

Ao analisar o IVCRS constata-se, também, que a região Centro-Oeste brasileira possui vantagem comparativa na exportação do óleo de soja. Pois, 
como demonstrado na Tabela 5, os valores obtidos através do Índice de Vantagem Simétrica foram positivos. Os valores do IVCRS oscilaram, no período analisado, entre 0,41 no ano de 2011 e 0,70 no ano de 2005.

Tabela 5 - Vantagem Comparativa Revelada e Vantagem Comparativa Revelada Simétrica para o óleo de soja, entre região a Centro-Oeste e o Brasil, período de 2002 a 2011

\begin{tabular}{l|c|c}
\hline ANOS & $\begin{array}{c}\text { IVCR } \\
\left(\mathbf{X}_{\mathbf{i j}} / \mathbf{X}_{\mathbf{j}}\right) /\left(\mathbf{X}_{\mathbf{i w}} / \mathbf{X}_{\mathbf{w}}\right)\end{array}$ & $\begin{array}{c}\text { IVCRS } \\
(\text { IVCR-1)/(IVCR+1) }\end{array}$ \\
\hline $\mathbf{2 0 0 2}$ & 3,18 & 0,52 \\
$\mathbf{2 0 0 3}$ & 3,36 & 0,54 \\
$\mathbf{2 0 0 4}$ & 4,68 & 0,65 \\
$\mathbf{2 0 0 5}$ & 5,77 & 0,70 \\
$\mathbf{2 0 0 6}$ & 3,83 & 0,59 \\
$\mathbf{2 0 0 7}$ & 3,45 & 0,55 \\
$\mathbf{2 0 0 8}$ & 3,15 & 0,52 \\
$\mathbf{2 0 0 9}$ & 3,43 & 0,55 \\
$\mathbf{2 0 1 0}$ & 3,28 & 0,53 \\
$\mathbf{2 0 1 1}$ & 2,40 & 0,41 \\
\hline
\end{tabular}

Fonte: Resultados da pesquisa.

Enquanto os resultados obtidos neste estudo, do índice para o óleo de soja para a região Centro-Oeste, foram positivos e diferentes da unidade, no estudo de Dorneles, Dalazoana e Schlindwein (2013) os resultados apresentados mostraram que o estado de Mato Grosso do Sul não possui vantagem em exportar o óleo de soja. Pois os produtos in natura recebem incentivos que as tornam mais vantajosas na hora da exportação, como o Imposto de Circulação da Mercadoria e Serviço (ICMS). Outro fator apontado como influenciador da desvantagem é a baixa capacidade industrial para este segmento no estado.

Em comparação à soja em grão, os valores do IVCR e IVCRS do óleo de soja foram inferiores. Mas, ao comparar os valores para os anos de 2002 e 2011, percebe-se que essa diferença está diminuindo nos últimos anos analisados. No ano de 2011, para a soja em grão, o índice atingiu um IVCRS de 0,56 (Figura 4), e para o óleo de soja 0,41(Figura 5). Mesmo assim, pode-se destacar que, a região deveria investir mais na produção deste bem, uma vez que possui maior valor agregado que o grão.

Ao comparar o período de 2002 com 2011, em termos de óleo de soja, verifica-se que ocorreram quedas em ambos os índices, conforme os dados apresentados na Figura 5. No que se refere ao Índice de Vantagens Comparativas Reveladas a queda foi de $24,53 \%$ e para o Índice de Vantagens Comparativas Reveladas Simétricas foi de 21,15\%, entre 2002 e 2011. 
Figura 5 - Comparação da evolução do IVCR e IVCRS para o óleo de soja, entre a região Centro-Oeste e Brasil, período de 2002 à 2011.

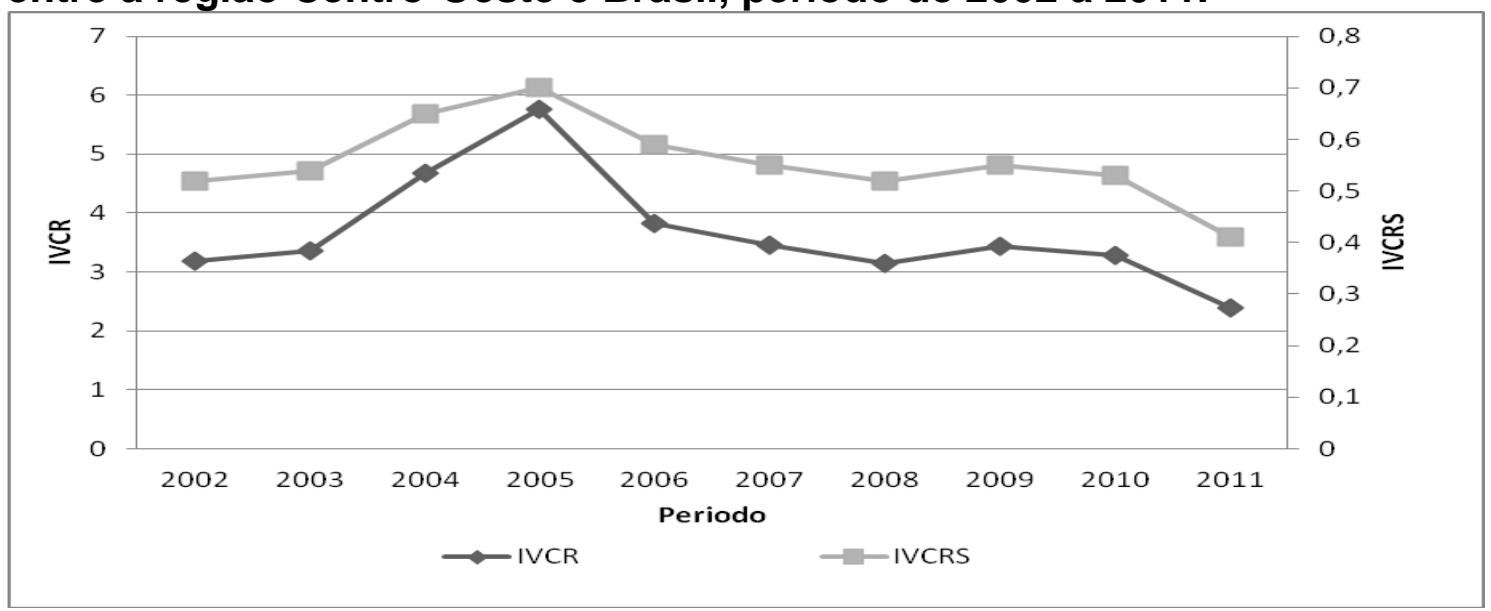

Fonte: Resultados da pesquisa.

Conforme já indicado em outros estudos, essa oscilação na exportação do óleo de soja pode ser justificada pela oscilação do consumo interno brasileiro. E, também, por problemas conjunturais, sendo maiores os incentivos públicos destinados à exportação dos produtos in natura, através da redução do Imposto de Circulação da Mercadoria e Serviço (ICMS). Além disso, a própria capacidade industrial brasileira para agregação de valor do produto. Conforme já apontado, o país está nadando contra a corrente, pois enquanto ele exporta produtos in natura, seus concorrentes estão procurando exportar produtos do complexo soja com valor agregado maior.

O último produto analisado foi o farelo da soja, cujos dados estão apresentados na Tabela 6. O Índice de Vantagem Comparativa Revelada demonstrou que a região Centro-Oeste também possui vantagem na exportação do farelo da soja. E, ainda, que este pode ser um importante item na pauta de exportação na região.

O IVCR mostrou bastante oscilação no que se refere ao farelo de soja. Apresentou pico em $2006 \mathrm{com} \mathrm{7,02} \mathrm{e,} \mathrm{o} \mathrm{menor} \mathrm{valor,} \mathrm{no} \mathrm{ano} \mathrm{de} \mathrm{2011,} \mathrm{foi} \mathrm{de}$ 3,58 , conforme a Tabela 6. O IVCRS apresentou valores positivos e, com exceção do ano de 2011, foram valores próximos à unidade. Indicando, assim, que a região Centro-Oeste possui forte vantagem comparativa na exportação deste produto.

Essa queda nos índices no ano de 2011 pode ser explicado, de acordo com Doneles, Dalazoana e Schlindwein (2013), pelo aumento do consumo interno do produto. Principalmente pelo setor de carnes que demanda farelo para a alimentação dos animais. Sendo este setor de carnes um item muito importante na pauta de exportação brasileira.

Constatou-se com este estudo que, tanto o grão da soja, como o óleo e o farelo, apresentou queda no IVCR, entre os anos de 2002 e 2011. A explicação para esse acontecimento pode ser obtida através da análise dos produtos que compõe a pauta de exportação da região Centro-Oeste. Assim destaca-se que, no ano de 2002, os produtos do complexo soja estavam mais concentrados entre os primeiros na pauta de exportação regional. Por exemplo, o óleo de soja bruto era o quarto produto mais exportado no ano de 2002, 
caindo para o décimo lugar no período de 2011. Enquanto, outros produtos como o milho em grão e o açúcar da cana que, em 2002, ocupavam, respectivamente, o vigésimo (20) e o vigésimo segundo (22ํ) lugar, passaram a ocupar o terceiro o quinto lugar (MDIC, 2011).

Tabela 6 - Vantagem Comparativa Revelada e Vantagem Comparativa Revelada Simétrica do farelo de soja para a região Centro-Oeste e o Brasil, período de 2002 a 2011

\begin{tabular}{l|c|c}
\hline ANOS & $\begin{array}{c}\text { IVCR } \\
\left(\mathbf{X}_{\mathbf{i j}} / \mathbf{X}_{\mathbf{j}}\right) /\left(\mathbf{X}_{\mathbf{i w}} / \mathbf{X}_{\mathbf{w}}\right)\end{array}$ & $\begin{array}{c}\text { IVCRS } \\
(\mathbf{I V C R}-\mathbf{1}) /(\mathbf{I V C R}+\mathbf{1})\end{array}$ \\
\hline $\mathbf{2 0 0 2}$ & 6,23 & 0,72 \\
$\mathbf{2 0 0 3}$ & 5,78 & 0,70 \\
$\mathbf{2 0 0 4}$ & 5,76 & 0,70 \\
$\mathbf{2 0 0 5}$ & 6,64 & 0,74 \\
$\mathbf{2 0 0 6}$ & 7,02 & 0,75 \\
$\mathbf{2 0 0 7}$ & 6,23 & 0,72 \\
$\mathbf{2 0 0 8}$ & 6,23 & 0,72 \\
$\mathbf{2 0 0 9}$ & 5,21 & 0,68 \\
$\mathbf{2 0 1 0}$ & 6,18 & 0,72 \\
$\mathbf{2 0 1 1}$ & 3,58 & 0,56 \\
\hline
\end{tabular}

Fonte: Resultados da pesquisa.

Além disso, como vários pontos foram levantados neste estudo que podem explicar essa queda nos índices de vantagens comparativas, como pode se destacar nível do consumo interno, que pode influenciar no volume de exportação. Também tem o problema da capacidade interna de produção de produtos com mais valores agregados. Além, de incentivos à exportação de produtos in natura, desestimulando a produção de produtos processados do complexo soja.

Entre os três produtos analisados - soja em grãos, óleo de soja e farelo - este último foi o que apresentou o melhor índice de vantagem. Podendo indicar que a região Centro-Oeste possui maior vantagem, entre os produtos do complexo soja, em exportar o farelo de soja. A região deveria aproveitar a crescente demanda mundial por este produto e investir mais em técnicas de aperfeiçoamento da produção e, principalmente, em melhorias na logística de escoamento do produto até aos portos.

Ao comparar a evolução do IVCR e do IVCRS, conforme a Figura 6, para o farelo de soja constata-se que, apesar das oscilações, se manteve um pouco constante até o período de 2010 , quando ocorre uma queda $(42,07 \%)$ entre 2010 e 2011.

Ao analisar a pauta de exportação da região Centro-Oeste no ano de 2011, verificou-se que, o valor da exportação do farelo de soja, aumentou $3,32 \%$ em relação ao ano anterior, foi um crescimento tímido em relação aos demais principais produtos exportados. Apesar do aumento no valor exportado, a participação do farelo de soja na pauta de exportação caiu de $14,46 \%$ no ano de 2010, para 11,21\% em 2011 (MDIC, 2011). 
Figura 6 - Comparação da evolução do IVCR E IVCRS para o farelo de soja, entre a região Centro-Oeste e Brasil, período de 2002 a 2011.

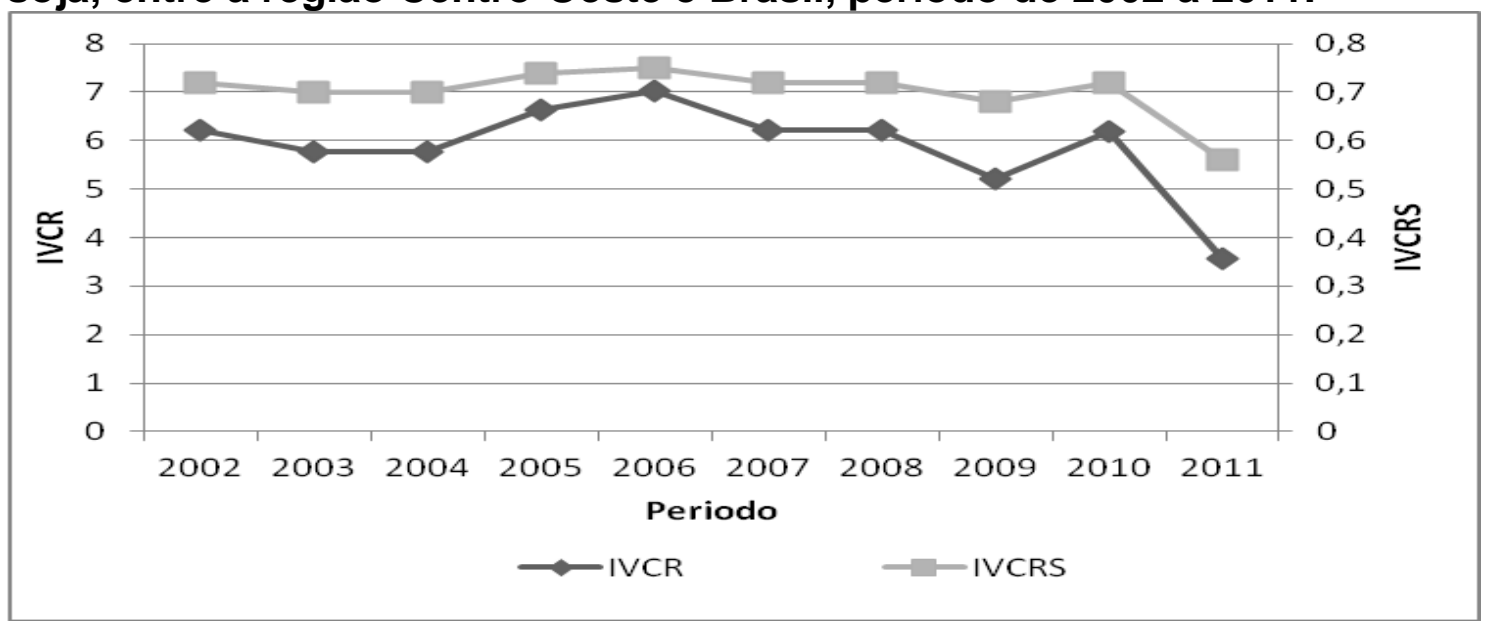

Fonte: Resultados da pesquisa.

Ao comparar o período de 2002 com o ano de 2011, e considerando o farelo de soja, verifica-se que ocorreu queda no índice neste período, conforme pode ser observado na Figura 6. Indica assim, que é preciso ficar em alerta, caso continue a diminuir esse índice. No estudo de Dorneles, Dalazoana e Schlindwein (2013), pode-se destacar que o Índice também foi superior a unidade em todo o período, 1997 a 2011. Porém, o índice também está apresentando queda nos últimos anos para o estado de Mato Grosso do Sul. Essa queda é apontada no estudo como um reflexo do aumento na demanda do setor de carnes no Brasil que depende do farelo para alimentar os animais.

\section{CONSIDERAÇÕES FINAIS}

Os dados analisados nesta pesquisa confirmam a importância da região Centro-Oeste no que se refere ao complexo soja. No que se refere à exportação de soja em grão da região Centro-Oeste, destaque-se que a participação desta região na pauta brasileira de exportação deste grão aumentou, chegando a $41,04 \%$ no ano de 2011.

O valor da exportação do óleo de soja também apresentou crescimento na participação ao comparar com a exportação nacional do produto, atingindo $27,92 \%$ no ultimo período, ano de 2011. Para o farelo de soja a exportação da região Centro-Oeste representou $41,70 \%$ da exportação nacional do produto no ano de 2011.

Contudo, deve-se destacar que ao comparar a exportação tanto do grão como do óleo e do farelo de soja da região Centro-Oeste ao total da exportação regional, percebe-se que estes produtos obtiveram diminuição em sua representatividade na pauta de exportação regional, durante o período de 2002 a 2011.

A partir desse panorama, utilizou-se o Índice de Vantagem Comparativa Revelada (IVCR) e o Índice de Vantagem Comparativa Revelada Simétrica (IVCRS), para analisar se a região Centro-Oeste possui ou não vantagem em 
exportar esses produtos muito importantes de sua pauta de exportação. Assim, todos os produtos do complexo soja apresentaram valores positivos e diferentes da unidade no IVCR. E, por sua vez, o IVCRS destes produtos apresentou valores que estão contidos dentro do intervalo de 0 e 1.

Indicando, assim, que a região Centro-Oeste possui vantagem comparativa para a exportação dos produtos do complexo soja. Deve-se destacar, no entanto, que em todos os produtos analisados ocorreu queda no IVCR durante o período de 2002 a 2011. Isso pode estar ocorrendo, devido aos produtos do complexo soja estarem perdendo um pouco de sua representação no total exportado pela região Centro-Oeste. Uma vez que produtos como o milho e o açúcar de cana estão ganhando espaço na pauta de exportação.

\section{REFERÊNCIAS}

BALASSA, B. Trade Liberalization and Revelead Comparative Advantage. Banco Mundial, Washington, D.C, 1965.

COMPANHIA NACIONAL DE ABASTECIMENTO - CONAB. Acompanhamento da safra brasileira: grãos Safra 2007/2008. $12^{\circ}$ Levantamento. Brasília, 37 p. Setembro/2008. Disponível em: <http://www.conab.gov.br/OlalaCMS/uploads/arquivos/cf60c3910a1354f2bcb08 0787a6107fc..pdf>. Acesso em: 28/04/2015.

Acompanhamento da safra brasileira: grãos Safra 2014/15. 6응 levantamento. Brasília, 103 p. março/2015. Disponível em <http://www.conab.gov.br/OlalaCMS/uploads/arquivos/15_03_11_14_07_48_bo letim_graos_marco_2015.pdf>. Acesso em 11/03/2015.

Séries Históricas. Brasília: CONAB, 2012. Disponível em: <http://www.conab.gov.br>. Acesso em: 28/04/2013.

CORONEL, D. A. et. al. A competitividade da produção de soja no Mato Grosso do Sul e na região de Ponta Porã: uma abordagem através da Vantagens Comparativas. In: XLV Congresso da Sociedade Brasileira de Economia e Sociologia Rural. Londrina, Anais, 2007. P 01-16.

Vantagens comparativas reveladas e orientação regional das exportações do complexo soja BRASILEIRO. In: XLIX Congresso da Sociedade Brasileira de Economia e Sociologia Rural. Porto Alegre - RS, Anais, 2009.

DIETER, M.; ENGLERT, H. Competitiveness in the global forest industry sector: an empirical study with special emphasis on Germany. European Journal of Forest Research, v.126, p. 401-412, Nov. 2006.

DORNELES, T.M.; DALAZOANA, F. M. L; SCHLINDWEIN, M. M. Análise do Índice de Vantagem Comparativa Revelada para o complexo da soja sulmato-grossense. Revista de Economia Agrícola. São Paulo, v.60, n.1, p 5-15, 2013. 
FILHO, J.F. BELIK, W. A política de tributação na exportação do complexo soja pelo Brasil: Transformação e Resultados. $48^{\circ}$ Congresso da Sociedade Brasileiro de Economia, Administração e Sociologia Rural (SOBER). Campo Grande/MS. 25-28 de Julho. 2010.

HAVRILA, I. GUNAWARDANA, P. Analysing Comparative Advantage and Competitiveness: An Application to Australia's Textile and Clothing Industries. Australia Economic Papers. V. 42. Issue 1. P.103-117. March:2003.

INSTITUTO BRASILEIRO DE GEOGRAFIA E ESTATISTICA - IBGE. Estimativa de população. 2014. Disponível em: <ftp://ftp.ibge.gov.br/Estimativas_de_Populacao/Estimativas_2014/estimativas_ 2014_TCU.pdf. >. Acesso em: 24/03/2015.

. Pesquisa Industrial Anual- Empresa 2012. Rio de Janeiro, v.31, n.1, p. 155-162, 2012. Disponível em: < $\mathrm{ftp}: / /$ ftp.ibge.gov.br/Industrias_Extrativas_e_de_Transformacao/Pesquisa_Indus trial_Anual/Empresa2012/piaempresa2012.pdf>. Acesso em: 17/02/2015.

Produção Agrícola Municipal - 2013. Rio de Janeiro, v.40, 102 p., 2013. Disponível em:

$\mathrm{ftp}: / / \mathrm{ftp}$. ibge.gov.br/Producao_Agricola/Producao_Agricola_Municipal_[anual]/2 013/pam2013.pdf>. Acessível em: 14/02/2015.

LAURSEN, K. Revealed Comparative Advantage and the Alternatives as Measures of International Specialization. Working Paper, n.98-30, Conpenhagem: Danish Research Unit for Industrial Dynamics, 1998.

MAIA, Jaime de Mariz. Economia internacional e comércio exterior. São Paulo: Atlas, 2001.

MESQUITA, C. W. Vantagem Comparativa Revelada: uma Análise do Perfil de Goiás. Conjuntura econômica goiana: boletim trimestral. n.7. Goiânia. Fevereiro, $2006 . \quad$ p. 28-32. Disponível em: <http://www.seplan.go.gov.br/sepin/down/Conjuntura7.pdf> Acesso em: 22/02/2013.

MINISTÉRIO DA AGRICULTURA, PECUÁRIA E ABASTECIMENTO - MAPA. Estatísticas dados básicos de economia agrícola: Fevereiro 2015. Secretária de Política Agrícola. Disponível em: <http://www.agricultura.gov.br/arq_editor/Pasta\%20de\%20Fevereiro\%20\%202015.pdf> Acesso em: 11/03/2014.

MINISTÉRIO DO DESENVOLVIMENTO, INDÚSTRIA E COMÉRCIO EXTERIOR - MDIC. Estatísticas de comercio exterior/DAEX: Balança comercial por Unidade da Federação. 2002. Disponível em: $<$ http://www.desenvolvimento.gov.br//sitio/interna/interna. $p h p$ ?area $=5 \&$ menu=1 076>. Acesso: 08/12/2013.

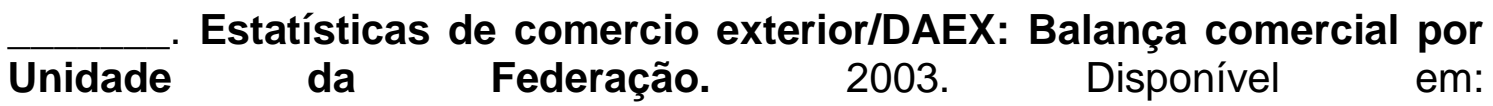
$<$ http://www.desenvolvimento.gov.br//sitio/interna/interna. php?area=5\&menu=1 076>. Acesso: 08/12/2013.

Unidade da $\quad$ Federação. $2004 . \quad$ Disponível em:


$<$ http://www.desenvolvimento.gov.br//sitio/interna/interna.php?area=5\&menu=1 076 >. Acesso: 08/12/2013.

. Estatísticas de comercio exterior/DAEX: Balança comercial por Unidade da Federação. 2005. Disponível em: $<$ http://www.desenvolvimento.gov.br//sitio/interna/interna.php?area=5\&menu=1 076 >. Acesso: 08/12/2013.

. Estatísticas de comercio exterior/DAEX: Balança comercial por Unidade da Federação. 2006. Disponível em: $<$ http://www.desenvolvimento.gov.br//sitio/interna/interna.php?area $=5 \&$ menu=1 076>. Acesso: 08/12/2013.

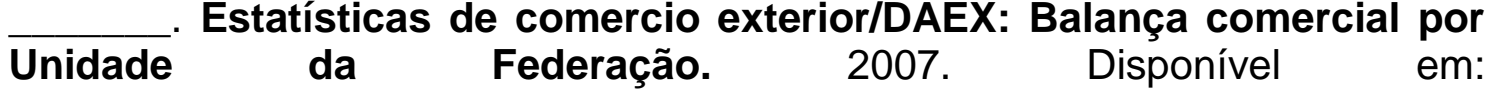
$<$ http://www.desenvolvimento.gov.br//sitio/interna/interna.php?area=5\&menu=1 076 >. Acesso: 08/12/2013.

. Estatísticas de comercio exterior/DAEX: Balança comercial por Unidade da Federação. 2008. Disponível em: $<$ http://www.desenvolvimento.gov.br//sitio/interna/interna.php?area=5\&menu=1 076>. Acesso: 08/12/2013.

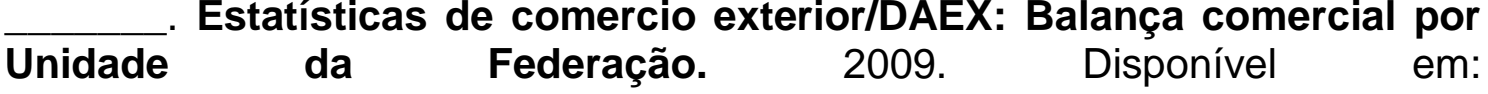
$<$ http://www.desenvolvimento.gov.br//sitio/interna/interna.php?area=5\&menu=1 076>. Acesso: 08/12/2013.

Unidade Estatísticas de comercio exterior/DAEX: Balança comercial por $<$ http://www.desenvolvimento.gov.br//sitio/interna/interna. php?area=5\&menu=1 076>. Acesso: 08/12/2013.

. Estatísticas de comercio exterior/DAEX: Balança comercial por Unidade da Federação. 2011. Disponível em: $<$ http://www.desenvolvimento.gov.br//sitio/interna/interna. php?area $=5 \&$ menu=1 076>. Acesso: 08/12/2013.

Unidade da Federação. 2015. Disponível em: $<$ http://www.desenvolvimento.gov.br//sitio/interna/interna. php?area=5\&menu=1 076>. Acesso: 11/03/2015.

MOSOMA, K. AGRICULTURAL COMPETITIVENESS AND SUPPLY CHAIN INTEGRATION: SOUTH AFRICA, ARGENTINA AND AUSTRALIA, Agrekon: Agricultural Economics Research, Policy and Practice in Southern Africa. ed. 43, v.1, p.132-144, 2004.

NONNEMBERG, M. J. Vantagens Comparativas Reveladas, Custo Relativo de Fatores e Intensidade de Recursos Naturais: Resultados para o Brasil - 1980/88. Rio de Janeiro: IPEA, Abril 1991 (Texto para Discussão, 214).

SISTEMA DE ANÁLISE DAS INFORMAÇÕES DE COMÉRCIO EXTERIOR VIA WEB/ ALICEWeb. Consulta. 2013. Disponível em: < http://aliceweb2.mdic.gov.br/>. Acesso em: 09/12/2013. 
SOUZA, M.J.P; ILHA, A. S. Índice de Vantagem Comparativa Revelada e de Orientação Regional para alguns produtos do agronegócio brasileiro no período de 1992 a 2002. Rio Grande do Sul, 2005. Disponível em: $<\mathrm{http} /$ www.ufsm.br/mila/adayr/publicações/científicos/vantagemcomparativa.pd f>. Aceso em: 15/09/2008.

TONHÁ, H. M. et. al. Vantagem Comparativa Revelada da carne bovina brasileira. Conjuntura econômica goiana. Goiânia. Seplan. n,15. Setembro2010. P 54-64.

WAQUIL, P. D. et. al. Vantagens Comparativas Reveladas e Orientação Regional das Exportações Agrícolas brasileiras para a União Europeia. Revista de economia e agronegócio. n.2, p. 137-160, 2004.

WORLD TRADE ORGANIZATION. Statistics database. Disponível em: $<$ http://stat.wto.org/Home/WSDBHome.aspx?Language=E>. Acesso em: 17/10/2013. 